\title{
Employee job satisfaction at Florida for-profit and not-for-profit hospitals
}

\author{
Elena A. Platonova*1, Kailas Venkitasubramanian ${ }^{2}$, Michael E. Thompson ${ }^{1}$ \\ ${ }^{1}$ Department of Public Health Sciences, University of North Carolina at Charlotte, United States \\ ${ }^{2}$ Project Mosaic, University of North Carolina at Charlotte, United States
}

Received: March 6, 2020

DOI: $10.5430 /$ jha.v9n2p33
Accepted: April 8, 2020

Online Published: April 21, 2020

\begin{abstract}
High quality health care requires competent, motivated, and satisfied health care employees. This research examines whether employee job satisfaction differs at for-profit (FP) and not-for-profit (NFP) hospitals and how other organizational characteristics mediate this relationship. In this cross-sectional study, Press Ganey Employee Partnership Survey data from 35 Florida hospitals were used to understand the relationship between hospital ownership (primary independent variable) and employee job satisfaction (outcome). A flexible structural equation model was used to examine the relationship. The sample included 32,892 valid responses (approximately 23\% from FP hospitals). Employees in FP hospitals were found to less satisfied with their jobs than their NFP counterparts. This trend was strongly associated with an inverse relationship between job satisfaction and assessment of immediate supervisors. The resulting job satisfaction model had an $R^{2}$ of 0.524 , indicating good fit. Further analyses revealed a positive association between perceived staffing levels and supervisor satisfaction, suggesting that the relative leanness of FP institutions might explain the observed difference in supervisor satisfaction. Employee job satisfaction is a complex multifaceted construct. Four main organizational factors affect employee job satisfaction: the organization's ownership type (FP or NFP), employee relationships with supervisors, work schedule, and length of employment. Leaders need to provide front line supervisors with adequate resources and support. Training immediate supervisors how to approach and be supportive of their workers provides an immediate solution toward increasing employee job satisfaction.
\end{abstract}

Key Words: For-profit and not-for-profit hospitals, Supervisor support, Hospital employee job satisfaction

\section{INTRODUCTION}

Employee job satisfaction is a complex, multifaceted construct which encompasses employee' evaluation of the work environment (job responsibilities and autonomy), leadership and management (strategy development and management support), and work group environment (social support and interpersonal relationships at work). ${ }^{[1,2]}$ High employee job satisfaction is associated with higher quality of care and improved clinical outcomes. ${ }^{[3]}$ Satisfied employees are also more committed and less likely to leave the organization. ${ }^{[2,4]}$ In contrast, dissatisfied workers are more likely to make clinical errors, which result in worse patient outcomes and higher turnover. ${ }^{[5-7]}$

Four main organizational factors affect employee job satisfaction: the organization's ownership type, employee relationships with managers, work schedule, and length of employment with the organization. Benz ${ }^{[8]}$ found that individuals working in FP health care companies were 8\%

\footnotetext{
* Correspondence: Elena A. Platonova; Email: eplatono@uncc.edu; Address: Department of Public Health Sciences, University of North Carolina at Charlotte, United States.
} 
less satisfied with their jobs than their not-for-profit (NFP) counterparts. Similar research in long-term care found that nursing aid turnover was 1.7 times higher among FP nursing homes and that employees working at NFP long-term care facilities are more satisfied with their jobs than their FP counterparts. ${ }^{[9-11]}$ Furthermore, Registered Nurses (RNs) in FP nursing homes had lower job satisfaction and were more likely to leave the profession. ${ }^{[1,12,13]}$ Similarly, FP nursing home directors were less satisfied and more likely to quit than their NFP counterparts. ${ }^{[14]}$

Employee relationships with immediate managers/supervisors influence employee job satisfaction and commitment to the organization. ${ }^{[2]}$ Good interpersonal relationships with immediate supervisors are associated with higher employee job satisfaction and lower turnover. ${ }^{[2,15-19]}$ Similarly, positive supervisor-nurse relationships significantly contributed to nurses' commitment to the hospital, which is why immediate supervisors play a major role in nursing turnover at US hospitals. ${ }^{[16,20]}$ Interestingly, good interpersonal relationships with immediate supervisors in assisted living facilities were more important for employees than other organizational characteristics such as training, promotional opportunities, benefits, and compensation, among others. ${ }^{[1]}$

High-quality supervisor-employee relationships are characterized by trust, open communication, training opportunities, and supervisor support. ${ }^{[19]}$ Supervisor support is critical in designing and maintaining organizational structures, distributing organizational resources among workers, and creating and maintaining a supportive organizational environment to provide high quality patient care. ${ }^{[16]}$ Supervisor support is needed for employees to be productive, satisfied, and committed to the organization. ${ }^{[2]}$ Supervisors may provide instrumental or emotional support. Instrumental support includes provision of necessary resources (e.g., adequate staffing and materials) and decision-making to improve work processes (e.g., efficient scheduling and distribution of resources, and work overload reduction). ${ }^{[1,16]}$ Emotional support encompasses acceptance, encouragement, and caring.

Supportive supervisors are perceived as good leaders by nurses. ${ }^{[12]}$ Immediate supervisor support is crucial for a successful implementation of a rapid organizational change. ${ }^{[21]}$ Current research indicates that supportive supervision results in higher employee job satisfaction and commitment to health care organizations ${ }^{[2,4,16,17,22-24]}$ Supportive supervision is associated with higher organizational involvement of nurses and lower professional burnout. ${ }^{[17,18,25]}$

Working night shifts detracts from employee satisfaction and effectiveness. Night shifts are associated with employee sleep deprivation, increased clinical errors, and poorer per- formance. ${ }^{[26-28]}$ Night shifts are associated not only with increased exhaustion and poor quality of sleep but also with lower employee job satisfaction. ${ }^{[26,29]}$ Employee organizational tenure/length of employment influence job satisfaction, although this relationship is complex since tenure itself likely reflects a prior period of satisfaction: findings range from inconsistent to contradictory, including positive, negative, cyclical, or no relationship between employee organizational tenure and job satisfaction. ${ }^{[30]}$

This research examines whether employee job satisfaction differed at FP and NFP Florida hospitals prior to the Patient Protection and Affordable Care Act (ACA). We also examined how other organizational characteristics mediate this relationship. We used Press Ganey Employee Partnership Survey data to examine this relationship. Press Ganey Associates is a national leader in collecting health care employee satisfaction data. This instrument has been used for over 20 years and demonstrated good reliability and validity. ${ }^{[31]}$

\section{METHODS}

In this cross-sectional study, we used Employee Partnership Survey data from 35 Florida hospitals collected in 2009 and 2010. The Survey has seven sections and collects information on employee assessment of hospital leadership and management, availability of organizational resources, teamwork and employee job satisfaction using multidimensional scales. ${ }^{[31]}$ These data remain relevant, as the ACA has not fundamentally changed organizational dynamics and tensions between FP and NFP organizations. Our sample included 32,892 valid responses, about $23 \%$ of which were from FP hospital employees. The study was approved by the relevant Institutional Review Board.

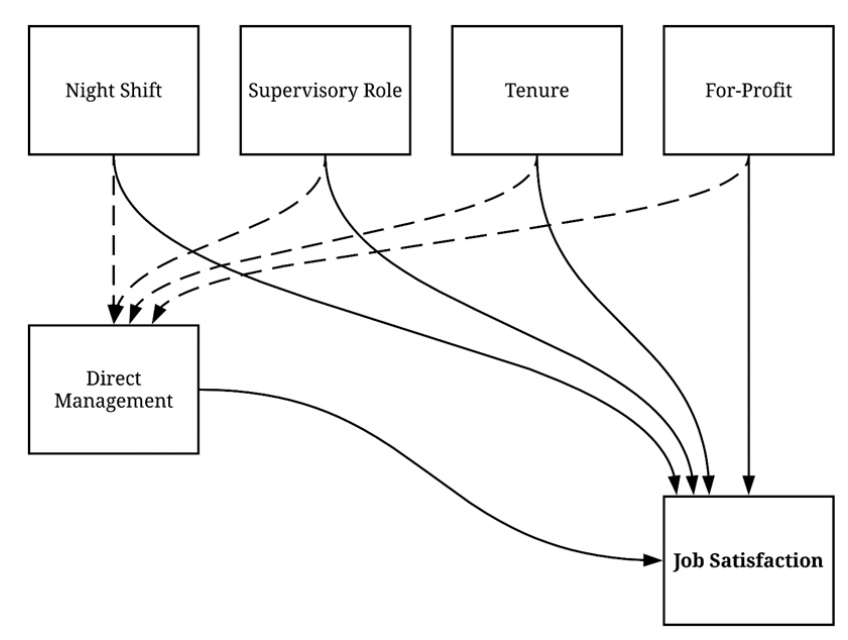

Figure 1. Empirical framework 


\subsection{Empirical model}

We proposed that FP organizational ownership type would negatively affect employee job satisfaction. We tested a flexible structural equation model to understand the relationship between hospital ownership and employee job satisfaction. The model incorporated both observed and latent (unobserved) variables and estimated relationships simultaneously, therefore representing and testing the model more efficiently.

We also hypothesized that an employee's satisfaction with or positive assessment of his or her direct supervisor/manager may influence job satisfaction. To test for this mediating effect, we controlled for other key factors related to employee job satisfaction as shown in Figure 1. We used statistical software MPlus (v.7.0) to estimate our models.

\subsection{Measures}

\subsubsection{Employee job satisfaction}

Our outcome variable (Employee job satisfaction) is a composite measure of six items from the Press Ganey Employee Partnership Survey (see Table 1). All items on the Survey range from "Strongly Disagree" to "Strongly Agree" (0-3) with higher scores indicating higher agreement. The latent variable created from these six items represents the measure of overall employee job satisfaction.

Table 1. Parameter estimates (Models of job satisfaction)

\begin{tabular}{|c|c|c|c|c|}
\hline \multirow{2}{*}{ Variables } & \multicolumn{2}{|c|}{ Model 1} & \multicolumn{2}{|c|}{ Model 2} \\
\hline & Std. estimate & $p$-value & Std. estimate & $p$-value \\
\hline \multicolumn{5}{|l|}{ Measurement model } \\
\hline \multicolumn{5}{|l|}{ Job satisfaction (MW) } \\
\hline - MW2 & 0.891 & .000 & 0.891 & .000 \\
\hline - MW3 & 0.928 & .000 & 0.926 & .000 \\
\hline - MW4 & 0.93 & .000 & 0.929 & .000 \\
\hline - MW5 & 0.733 & .000 & 0.733 & .000 \\
\hline - MW6 & 0.896 & .000 & 0.895 & .000 \\
\hline \multicolumn{5}{|l|}{ Direct management (DM) } \\
\hline - DM1 & 0.949 & .000 & 0.949 & .000 \\
\hline - DM2 & 0.941 & .000 & 0.941 & .000 \\
\hline - DM3 & 0.952 & .000 & 0.951 & .000 \\
\hline - DM4 & 0.952 & .000 & 0.951 & .000 \\
\hline - DM5 & 0.953 & .000 & 0.952 & .000 \\
\hline - DM6 & 0.802 & .000 & 0.802 & .000 \\
\hline - DM7 & 0.936 & .000 & 0.936 & .000 \\
\hline \multicolumn{5}{|l|}{ Structural model } \\
\hline \multicolumn{5}{|l|}{ Job satisfaction (MW) } \\
\hline - Direct management (DM) & 0.712 & .000 & 0.632 & .000 \\
\hline - For profit & -0.105 & .000 & -0.042 & .000 \\
\hline - Supervisory role & 0.088 & .000 & 0.085 & .000 \\
\hline - Tenure (more than 10 years) & 0.085 & .000 & 0.071 & .000 \\
\hline - Night shift employee & 0.027 & .049 & 0.037 & .005 \\
\hline - Adequate staffing & & & 0.178 & .000 \\
\hline \multicolumn{5}{|l|}{ Direct management (DM) } \\
\hline - For profit & -0.231 & .000 & -0.007 & .578 \\
\hline - Supervisory role & 0.366 & .000 & 0.275 & .000 \\
\hline - Tenure (more than 10 years) & 0.065 & .000 & 0.009 & .479 \\
\hline - Night shift employee & -0.133 & .000 & -0.077 & .000 \\
\hline - Adequate staffing & & & 0.493 & .000 \\
\hline
\end{tabular}




\subsubsection{Hospital ownership}

We used a binary variable for our key independent variable (Hospital ownership type) that indicates whether the employee worked in a FP or NFP hospital, setting NFP as the referent.

\subsubsection{Direct management}

We measured employees' assessment of their direct supervisors using a composite measure of seven items from the survey. This latent variable measures the overall employee assessment of the employee-direct supervisor relationship with higher scores indicating a more positive relationship.

\subsubsection{Control variables}

Using binary indicators, we measured whether an employee was in a supervisory position and whether he/she regularly worked night or day shifts. We also controlled for employee job tenure/length of employment at the hospital $(\geq 10$ years vs. $<10$ years $)$.

\subsection{Model specification}

The structural equation in Figure 2 integrates measurement of multi-dimensional constructs and estimates direct and indirect relationships in a single model. We first tested measurement models for employee job satisfaction and assessment of direct supervisors separately using their respective scales to ensure good fit. We then specified the full regression model where the measurement model for job satisfaction and direct management and their predictors were included for parameter estimation. We tested employee how job satisfaction differed between FP and NFP hospitals. Figure 2 also summarizes the resulting coefficients. Table 1 (Model 1) reports those parameter estimates in detail.

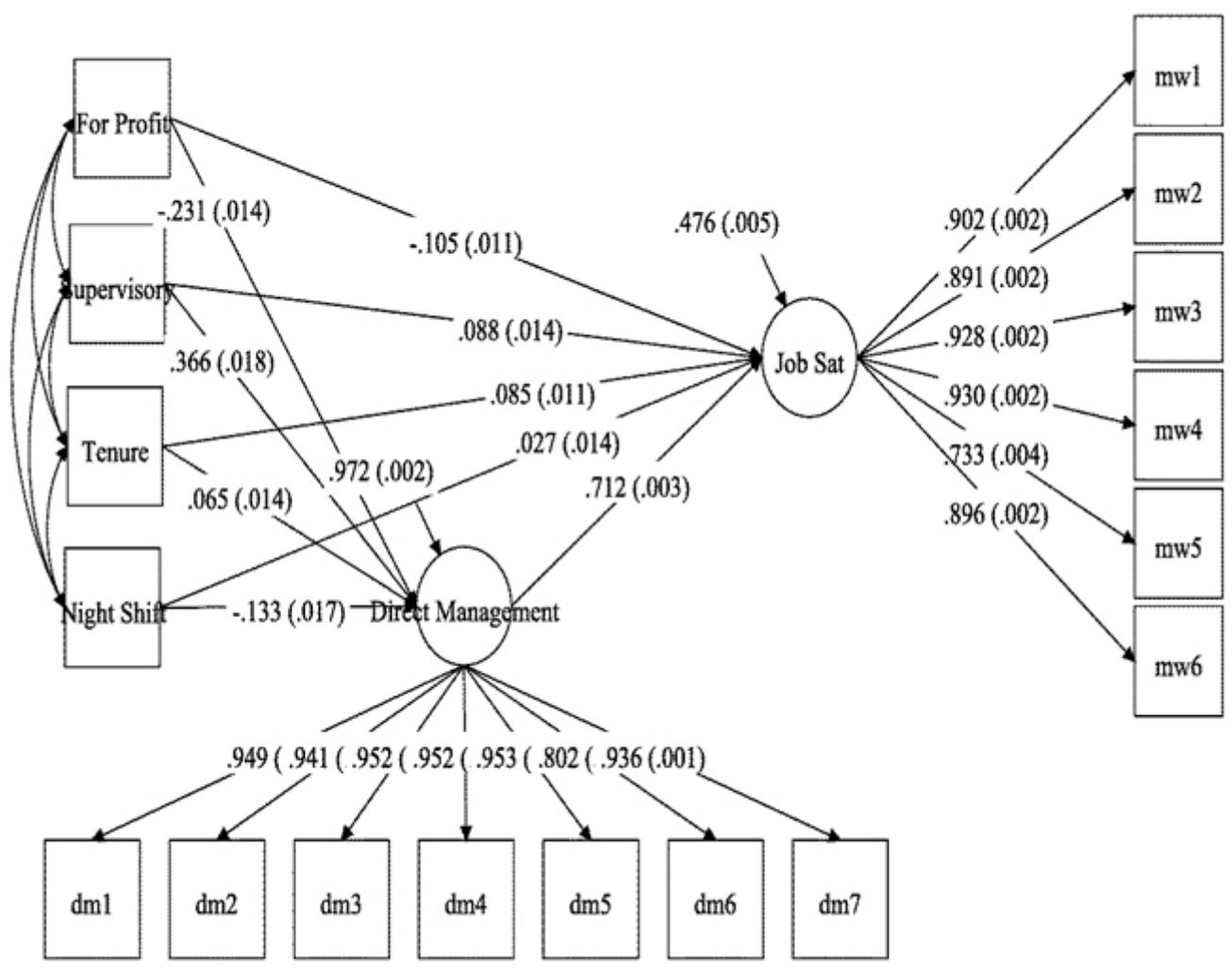

Figure 2. Specification and parameter estimates (Model 1)

\section{RESULTS}

We found that employees in FP Florida hospitals were less satisfied with their jobs than employees in NFP hospitals (see Table 1, Model 1, Structural model). FP hospital employees on average had about 0.1 standard deviations lower job satisfaction than their NFP counterparts. We also found that employees in FP hospitals had less positive assessment of their immediate/direct supervisors: on average 0.231 standard deviations less positive assessment compared with NFP employees. Third, we found that a positive assessment of the direct supervisor/manager increased job satisfaction significantly. On average, one standard deviation increase in positive assessment of immediate supervisors increased employee job satisfaction by 0.712 standard deviations. These results were statistically significant, implying that employee job satisfaction was affected directly and indirectly by the organization ownership type. The statistically significant indirect effect suggests that employee assessment of the im- 
mediate supervisors is a strong explanation for the observed differences in employee job satisfaction between FP and NFP hospitals.

We found that hospital workers in supervisory positions were characterized by higher job satisfaction: 0.088 standard deviation higher than for employees in non-supervisory positions. We also found that employees who had worked at a hospital for a longer time reported higher job satisfaction and assessed their direct supervisors more positively ( 0.085 standard deviations). However, employee job satisfaction was not affected by work shift. The job satisfaction model (see Table 1, Model 1) had an $R^{2}$ of 0.524 , indicating good fit and the relevance of specified variables in explaining employee job satisfaction in Florida hospitals.

Inspired by the findings in the model above, we investigated further by extending our hypothesis that FP hospitals, given their inclination to operate leaner, might be different from NFPs in the availability of organizational resources. ${ }^{[11]} \mathrm{We}$ hypothesized that business models based on profit-seeking may influence how organizational resources are managed and hence affect how employees work and interact with the hospital. This behavior in turn may influence employee job satisfaction. Thus, we tested whether the availability of adequate organizational resources could affect employee job satisfaction; specifically, we estimated a model (Model 2) including employee responses about staffing on their work unit "There is adequate staffing in my work group." We incorporated this variable as an additional predictor of employee job satisfaction and immediate supervisor assessment.

Figure 3 shows the model specification and Table 1 (Model 2, Structural model) shows parameter estimates. In this model, we found that employees working at FP hospitals continued to have lower job satisfaction than those working at NFPs. However, the magnitude of effect is significantly reduced: FP hospital employees reported about 0.04 standard deviations lower job satisfaction than NFP employees while previously the difference was 0.1 standard deviation. Simultaneously, one unit increase in adequacy of staffing perception was associated with 0.178 standard deviations increase in employer job satisfaction.

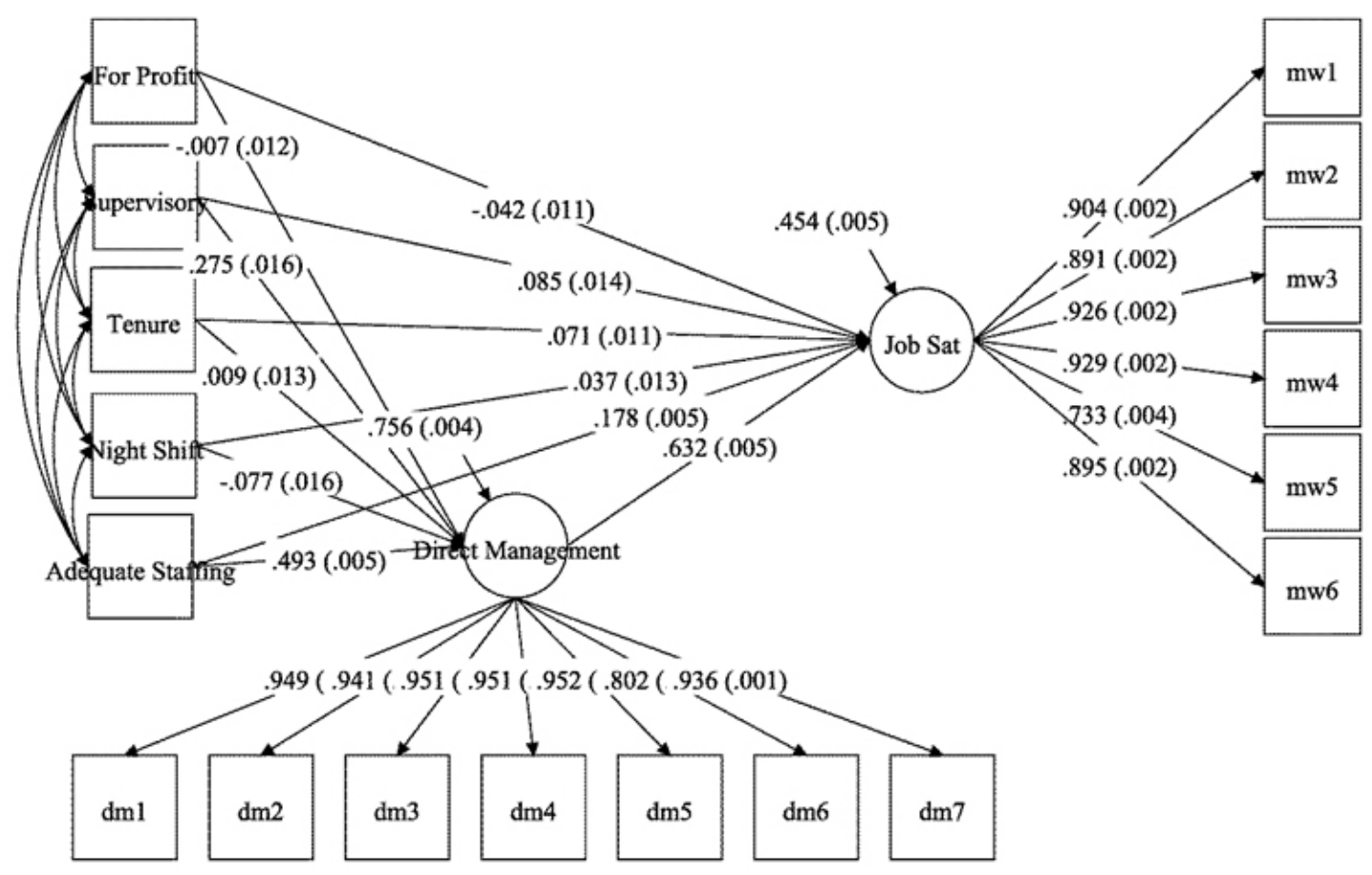

Figure 3. Specification and parameter estimates (Model 2)

Compared with other shifts, employees working night shifts provided less positive assessment of their immediate supervisors ( -0.133 and -0.077 standard deviations in Models 1 and 2 , respectively; $p=.000$ ). Interestingly, when the staffing variable was included in the model, the differences in employee assessments of immediate supervisors at FP and NFP hospitals were no longer significantly different. At the same time, we found that when employees felt their units were adequately staffed, they also assessed direct supervisors higher: one unit increase in adequacy of staffing was associated with 0.493 standard deviations increase in immediate supervisors/managers assessment. This finding may indicate that 
employee dissatisfaction at FP hospitals was due to the relative inadequacy of staffing in their work units. Thus, the earlier difference observed in Model 1 was most likely due to a different resource allocation model at FP hospitals. In support of that interpretation, we found that when staffing is adequate, longer employment at a hospital had no effect on employees' assessment of their immediate supervisors ( $p=$ $.479)$.

\section{Discussion}

We have developed a conceptual model that synthesizes and extends existing research on employee job satisfaction. In contrast to correlation-based studies, structural equation modeling with latent effects quantifies these relationships in their entirety. Our models demonstrated excellent fit to the data.

Employee job satisfaction is critical for organizational performance. ${ }^{[32]}$ Consistent with the literature, this study found that employees working at NFP hospitals were more satisfied than their peers working at FPs. Lower employee job satisfaction working in FP organizations may be explained by specific organizational cost control strategies such as lower compensation, fewer benefits, lower staffing levels, and less investment in employee training and development. ${ }^{[11]} \mathrm{Em}$ ployees in FP organizations have less autonomy and feel less empowered which may lead to decreased job satisfaction. ${ }^{[33]}$ In addition, NFP organizations offer important non-financial work benefits to their employees that may positively affect employee job satisfaction. ${ }^{[8]}$

Strong supervisor support is a must for the successful implementation of quality improvement initiatives. ${ }^{[21]}$ Our results indicate that supervisor support is not only an important factor directly affecting employee job satisfaction but also is a "buffer" that can mitigate negative organizational pressures and improves employee job satisfaction. Our results suggest that employees are more critical of their immediate managers when their units are understaffed. Thus, the role of direct management may be particularly important for employee job satisfaction in low-resource facilities, regardless of FP or NFP status.

We found that having adequate organizational resources such as staffing are essential for hospital employee job satisfaction. Adequate staffing is a must to provide high quality care, improved patient safety and clinical outcomes. ${ }^{[16,33-35]}$ Hospitals ranked in the top quartile had higher nurse-to-patient ratios and provided higher quality care, as demonstrated by fewer pressure ulcers and less missed care during inpatient stays. ${ }^{[35]}$ Adequate staffing is essential for RN job satisfaction, even when accounting for patient acuity and individual nurse characteristics (age, experience, etc. ${ }^{[36]}$ Nurses in the worst-staffed hospitals were 1.3 times more likely to rate the quality of care as fair or poor. ${ }^{[25]}$

Our study found that long hospital employment was associated with higher employee job satisfaction. However, long tenures did not affect employee assessment of immediate supervisors. A possible explanation of these results is that employees with long careers at an institution must have liked their hospitals and/or immediate supervisors enough to overlook those other shortcomings; otherwise they would have quit a long time before.

Our results confirm previous empirical evidence about lower assessment of immediate supervisors by employees working night shifts. Night work demands may be higher and those workers may have less control over their environment Night workers might also lose out on social buffers such as community involvement because of their work hours, which in turns negatively affects their perception of their immediate managers. ${ }^{[37]}$

\section{Strengths and limitations}

In addition to the innovation of using structural equations for such assessments, our findings are consistent with earlier research on employee job satisfaction in FP and NFP organizations and expand our knowledge on effective human resource management in the hospital sector. The sample size provided adequate power to test our hypotheses. Our study was conducted in one state using a convenience sample; thus, despite the large number of responses and robustness of the data, the results might not be generalizable to other hospitals in the nation.

\section{Conchusions}

High quality health care delivery requires competent, motivated, and satisfied health care employees. Leaders need to encourage best practices to maximize employee satisfaction, recognizing that some determinants (e.g., night shift) are an inherent and intractable challenge while others (e.g., supervisor-employee relations) can be ameliorated through improved management practices and staff professional development. Leaders also need to ensure they are providing front line supervisors adequate resources and support to accomplish their mission, to include maintaining employee morale and effectiveness. Training immediate supervisors/managers how to approach and be supportive of their workers provides an immediate solution toward increasing employee job satisfaction.

Despite the design and sampling limitations, we are confident that the inferences made from this study in Florida reflect the experience across the US healthcare system. 


\section{ACKNOWLEDGements}

We are grateful to Drs. Robert Wolosin and Bradley Fulton, formerly with Press Ganey Associates. Inc., for providing the data and related support needed to starting this project.

\section{CONFLICTS OF INTEREST Disclosure}

The authors declare they have no conflicts of interest.

\section{REFERENCES}

[1] Chou RJ, Robert SA. Workplace support, role overload, and job satisfaction of direct care workers in assisted living. Journal of Health and Social Behavior. 2008; 49(2): 208-222. PMid: 18649503. https://doi.org/10.1177/002214650804900207

[2] Weinberg DB, Avgar AC, Sugrue NM, et al. The importance of a high-performance work environment in hospitals. Health Services Research. 2013; 48(1): 319-322. PMid: 22716770. https: //doi.org/10.1111/j.1475-6773.2012.01438.x

[3] Aronson KR. Job satisfaction of nurses who work in private psychiatric hospitals. Psychiatric Services. 2005; 56(1): 102-104. PMid: 15637202. https://doi.org/10.1176/appi.ps.56.1.102

[4] Cowden TL, Cummings GG. Testing a theoretical model of clinical nurses' intent to stay. Health Care Management Review. 2015; 40(2): 169-181. PMid: 24566247 https://doi.org/10.1097/HMR. 00 00000000000008

[5] Cohn KH, Bethancourt B, Simington M. The lifelong iterative process pf physician retention. Journal of Healthcare Management. 2009; 54(4): 220-226. PMid: 19681354. https://doi.org/10.1097/ 00115514-200907000-00003

[6] Sattigeri RC, Kulkarni DG. Job satisfaction in hospital employees: a review of literature. International Journal of Engineering Technology Science and Research. 2017; 4(2): 27-30.

[7] Shinde M, Potdar N, Shete S. Job satisfaction among housekeeping workers in tertiary care hospital. International Journal of Science and Research. 2017; 6(2): 150-153.

[8] Benz M. Not for the profit, but for the satisfaction?- evidence on worker well-being in non-profit firms. Kyklos. 2005; 58(2): 155-176. https://doi.org/10.1111/j.0023-5962.2005.00283.x

[9] Banaszak-Holl J, Hines MA. Factors associated with nursing home staff turnover. Gerontologist. 1996; 36(4): 512-517. PMid: 8771979. https://doi.org/10.1093/geront/36.4.512

[10] Jang Y, Lee AA, Zadrozny M, et al. Determinants of job satisfaction and turnover intent in home health workers: the role of job demands and resources. Journal of Applied Gerontology. 2015; 36(1): 5670. PMid: 25956445. https://doi.org/10.1177/0733464815 586059

[11] Noelker LS, Ejaz FK, Menne HL, et al. Factors affecting frontline workers' satisfaction with supervision. Journal of Aging and Health 2009; 21(1): 85-101. PMid: 19144970. https://doi.org/10.1 $177 / 0898264308328641$

[12] Choi J, Flynn L, Aiken LH. Nursing practice environment and registered nurses' job satisfaction in nursing homes. Gerontologist. 2012; 52(4): 484-492. PMid: 21908803. https://doi.org/10.1093/ geront/gnr101

[13] Wendsche J, Hacker W, Wegge J, et al. High job demands and low job control increase nurses' professional leaving intentions: the role of care setting and profit orientation. Research in Nursing and Health. 2016; 39(5): 353-363. PMid: 27223817. https : //doi.org/10.1002/nur.21729

[14] Karsh B, Beasley JW, Brown RL. Employed family physician satisfaction and commitment to their practice, work group, and health care organization. Health Services Research. 2010; 45(2): 457-475. PMid: 20070386. https://doi.org/10.1111/j.1475-6773.2009.0 $1077 . \mathrm{x}$

[15] Han GH, Jekel M. The mediating role of job satisfaction between leader-member exchange and turnover intentions. Journal of Nursing Management. 2011; 19(1): 41-49. PMid: 21223404. https : //doi.org/10.1111/j.1365-2834.2010.01184.x

[16] Hunt D. Does value congruence between nurses and supervisors effect job satisfaction and turnover? Journal of Nursing Management 2014; 22(5): 572-582. PMid: 23829178. https://doi .org/10.1 $111 /$ jonm. 12055

[17] Pohl S, Galletta M. The role of supervisor emotional support on individual job satisfaction: a multilevel analysis. Applied Nursing Research. 2017; 33(6): 61-66. PMid: 28096025. https://doi.or $\mathrm{g} / 10.1016 / \mathrm{j} . \mathrm{apnr} .2016 \cdot 10.004$

[18] Scanlan JN, Still M. Job satisfaction, burnout and turnover intention in occupational therapists working in mental health. Australian Occupational Therapy Journal. 2013; 60(5): 310-318. PMid: 24089982 https://doi.org/10.1111/1440-1630.12067

[19] Stringer L. The link between the quality of the supervisor- employee relationship and the level of the employee's job satisfaction. Public Organization Review. 2006; 6(2): 125-142. https: //doi.org/10.1007/s11115-006-0005-0

[20] Brunetto Y, Shriberg A, Farr-Wharton R, et al. The importance of supervisor-nurse relationships, teamwork, wellbeing, affective commitment and retention of North American nurses. Journal of Nursing Management. 2013; 21(6): 827-837. PMid: 23890080 https://doi.org/10.1111/jonm.12111

[21] Stelson P, Hille J, Eseonu C, et al. What drives continuous improvement project success in healthcare? International Journal of Health Care Quality Assurance. 2017; 30(1): 43-57. PMid: 28105876 https://doi.org/10.1108/IJHCQA-03-2016-0035

[22] Djukic M, Jun J, Kovner C, et al. Determinants of job satisfaction for novice nurse managers employed in hospitals. Health Care Management Review. 2017; 42(2): 172-183. PMid: 26765480. https://doi.org/10.1097/HMR.0000000000000102

[23] Meeusen VC, Van Dam K, Brown-Mahoney C, et al. Understanding nurse anesthetists' intention to leave their job: how burnout and job satisfaction mediate the impact of personality and workplace characteristics. Health Care Management Review. 2011; 36(2): 155163. PMid: 21317664. https ://doi.org/10.1097/HMR.0b013e $3181 \mathrm{fb} 0 \mathrm{f} 41$

[24] Poghosyan L, Liu J, Shang J, et al. Practice environments and job satisfaction and turnover intentions of nurse practitioners: implications for primary care workforce capacity. Health Care Management Review. 2017; 42(2): 162-171. PMid: 26587998. https: //doi.org/10.1097/HMR.0000000000000094

[25] Aiken LH, Clarke SP, Sloane DM. Hospital staffing, organization and quality of care: cross- national findings. International Journal for Quality in Health Care. 2002; 14(1): 5-14. PMid: 11871630. https://doi.org/10.1093/intqhc/14.1.5

[26] Dall'Ora C, Ball J, Recio-Saucedo A, et al. Characteristics of shift work and their impact on employee performance and wellbeing: a 
literature review. International Journal of Nursing Studies. 2016; 57 : 12-27. PMid: 27045561. https ://doi.org/10.1016/j.ijnurs tu. 2016.01.007

[27] Johnson AL, Jung L, Song Y, et al. Sleep deprivation and error in nurses who work the night shift. Journal of Nursing Administration. 2014; 44(1): 17-22. PMid: 24316614. https ://doi.org/10.109 7/NNA. 0000000000000016

[28] Niu S, Chu H, Chen CH, et al. A comparison of the effects of fixedand rotating- shift schedules on nursing staff attention levels: a randomized trial. Biological Research for Nursing. 2012; 15(4): 443450. PMid: 22593230. https ://doi.org/10.1177/1099800412 445907

[29] Teclaw R, Osatuke K. Nurse perceptions of workplace environment: differences across shifts. Journal of Nursing Management. 2015; 23(8): 1137-1146. PMid: 25491124. https://doi.org/10.111 $1 /$ jonm. 12270

[30] Riza SD, Ganzach Y, Liu Y. Time and job satisfaction: a longitudinal study of the differential roles of age and tenure. Journal of Management. 2018; 44(7): 2558-2579. https://doi.org/10.1177/01 49206315624962

[31] Clark P, Wolosin R, Gavran G. Customer convergence: patients, physicians, and employees share in the experience and evaluation of healthcare quality. Health Marketing Quarterly. 2006; 23(3): 7999. PMid: 18681200. https://doi.org/10.1080/0735968080 2086257

[32] HR Daily Advisor. Strategic HR: How employee satisfaction effects organizational performance. June 2017. Available from: https://hrdailyadvisor.blr.com/2017/06/16/employee -satisfaction-affects-organizational-performance/

[33] Kalisch BJ, Lee H, Rochman M. Nursing staff teamwork and job satisfaction. Journal of Nursing Management. 2010; 18(8): 938947. PMid: 21073567. https://doi.org/10.1111/j.1365-2 834.2010.01153.x

[34] Martin CJ. The effects of nurse staffing on quality of care. MEDSURG Nursing. 2015; 24(2): s4-s6.

[35] Zolot J. Nurse perception of workplace safety affects patient care. American Journal of Nursing. 2017; 117(2): 14. https://doi .or $\mathrm{g} / 10.1097 / 01 . \mathrm{NAJ} .0000512286 .71113 .23$

[36] Kalisch B, Lee KH. Staffing and job satisfaction: nurses and nursing assistants. Journal of Nursing Management. 2014; 22(4): 465-471. PMid: 24809239. https ://doi.org/10.1111/jonm. 12012

[37] Cornwell B, Warburton E. Work schedules and community ties. Work and Occupations. 2014; 41(2): 139-174. https ://doi .org/10.1 $177 / 0730888413498399$ 